Research Article

\title{
Cognitive and psychomotor effects of adjunctive aripiprazole or paliperidone in patients of schizophrenia receiving olanzapine: a double blind placebo controlled clinical study
}

\author{
Mayur M. Mayabhate ${ }^{1 *}$, Vandana A. Badar ${ }^{1}$, Praveer Waradkar ${ }^{2}$, Abhishek Somani ${ }^{2}$
}

\begin{abstract}
${ }^{1}$ Department of Pharmacology, Indira Gandhi Government Medical College and Hospital, Nagpur-440018, Maharashtra, India,

${ }^{2}$ Department of Psychiatry, Indira Gandhi Government Medical College and Hospital, Nagpur440018, Maharashtra, India
\end{abstract}

Received: 2 December 2013 Accepted: 15 December 2013

*Correspondence to: Dr. Mayur M. Mayabhate, Email: drmayur2511@gmail.com

(C) 2014 Mayabhate MM et al. This is an open-access article distributed under the terms of the Creative Commons Attribution Non-Commercial License, which permits unrestricted noncommercial use, distribution, and reproduction in any medium, provided the original work is properly cited.

\begin{abstract}
Background: Emergence of atypical antipsychotics has revolutionized the treatment of schizophrenia by exploiting dual actions on serotonin as well as dopaminergic receptors. Still, monotherapy with these agents is insufficient to control cognitive and psychomotor as well as positive and negative symptoms. Hence combination therapy with antipsychotics is common in clinical practice. Objective of current study is to compare the effects of addition of aripiprazole or paliperidone on cognition and psychomotor functions in schizophrenia receiving olanzapine.

Methods: This is prospective, double blind, placebo controlled, parallel group study in 90 patients of schizophrenia showing partial or no response to olanzapine measured by Positive And Negative Symptoms Score (PANSS) scale. They were randomly divided to receive adjuvant aripiprazole, paliperidone or placebo for 6 weeks.

Results: Combination of aripiprazole and olanzapine shows significant improvement in most of the cognition and psychomotor parameters like attention, perception, verbal memory, thinking and processing as well as motor speed while combination of paliperidone and olanzapine is associated with improvement in only some of the cognitive and psychomotor parameters such as attention, perception and verbal memory only. Both the combinations are efficacious in controlling positive and negative symptoms of schizophrenia as assessed by PANSS scale.

Conclusions: The best augmenting strategy with for olanzapine nonresponsive patients will be $D_{2}$ receptor partial agonist like aripiprazole rather than $D_{2}$ antagonist like paliperidone and other atypical antipsychotic agents for better improvement in cognition and psychomotor domains.
\end{abstract}

Keywords: Schizophrenia, Cognition, Psychomotor function, Aripiprazole, Paliperidone

\section{INTRODUCTION}

Schizophrenia by definition is a disturbance that last for six months or longer, including at least one month of delusions, hallucinations, disorganized speech, grossly disorganized or catatonic behaviour or negative symptoms. It is one of the most debilitating psychiatric disorders and has long been the focus of medical, scientific and societal attention. It has devastating effects on both its victim and their families. Furthermore, it extracts enormous economic cost from the society. ${ }^{1,2}$ Although schizophrenia is an illness that has been historically characterized by the presence of positive and negative symptomatology, decades of research highlight the importance of cognitive and psychomotor deficits in this disorder. ${ }^{3}$

Cognitive function is the brains ability to acquire, process, integrate, store and retrieve information. Cognitive deficits are present in schizophrenia regardless of illness stage, as individuals experiencing their first episode of schizophrenia show a pattern of deficits on tasks related to frontal and temporal lobe functioning, including attention, processing speed, executive 
functioning, verbal fluency, verbal memory and learning. Deficits in these domains have been consistently associated with poor social functioning as well as poor work/school outcome. ${ }^{3,4}$ Psychomotor function includes sensorimotor processes such as reaction time and sensorimotor accuracy. Psychomotor slowing is also a recognized symptom of schizophrenia. ${ }^{5}$ Moreover, slowed psychomotor functioning is often not delineated from reduced processing speed and it may also become impaired for the same reasons as cognitive function.

Due to the introduction of atypical antipsychotics (AAPs) like olanzapine, clozapine, paliperidone, aripiprazole and others, it had become possible to exploit the dual action on serotonin as well as dopamine which has resulted in greatly increased compliance by minimizing the extrapyramidal side effects, a property that distinguishes them from conventional antipsychotics. ${ }^{2,6}$ Though the AAPs are highly effective in reducing various symptoms of schizophrenia, monotherapy with these agents may be insufficient to produce adequate response. Various studies report that, up to $40 \%$ of patients with schizophrenia have symptoms that are resistant to monotherapy. So, combination therapy, called antipsychotic polypharmacy is often used clinically. ${ }^{7-9}$

Olanzapine is an atypical antipsychotic effective against negative as well as positive symptoms of schizophrenia with little extrapyramidal side effects. ${ }^{10}$ It is one of the most commonly prescribed agents as a monotherapy in our hospital settings. Still, number of patients may remain partially responsive or unresponsive to olanzapine therapy. So, there is a need to augment olanzapine with other antipsychotic agents.

Aripiprazole is novel atypical antipsychotic having unique pharmacological profile. It has potent partial agonist activity at dopamine $\mathrm{D}_{2}$ and serotonin $5 \mathrm{HT}_{1 \mathrm{~A}}$ receptors and antagonist activity at $5 \mathrm{HT}_{2 \mathrm{~A}}$ receptors. Aripiprazole acts as a functional antagonist at $\mathrm{D}_{2}$ receptors under hyperdopaminergic conditions, but exhibits functional agonist properties under hypodopaminergic conditions. Thus, it acts as a dopamine-serotonin system stabilizer agent. ${ }^{11,12}$ It suppresses both positive and negative symptoms of schizophrenia. ${ }^{13}$ Recent studies have shown that, it produces improvement in neurocognition in patients of schizophrenia. ${ }^{14-16}$ Also, it has a favorable effect on metabolic parameters like body weight, serum lipid levels etc. which are major side effects of olanzapine like antipsychotic agents. ${ }^{17,18}$

Paliperidone, the major active metabolite of risperidone (9-hydroxyrisperidone), is a secondgeneration antipsychotic that was approved for treatment of acute schizophrenia and for maintenance treatment of schizophrenia. It also reduces positive and negative symptoms of schizophrenia measured by positive and negative symptom scale (PANSS). ${ }^{19}$ This is the first study, to best of our knowledge, measuring the cognitive benefits, if any, with paliperidone. Previous studies with parent drug risperidone showed that, it improves various parameters of cognitive and psychomotor function in patients of schizophrenia. ${ }^{20-22}$

Therefore, this prospective clinical study was carried out to compare the effects of addition of aripiprazole and paliperidone on cognitive and psychomotor functions in patients of schizophrenia receiving olanzapine.

\section{METHODS}

\section{Participants}

Inclusion criteria: All diagnosed patients of schizophrenia as per DSM-IV criteria of either sex between $20-60$ years of age, and educated at least up to $5^{\text {th }}$ standard willing to participate in the study and receiving olanzapine for at least 6 weeks and showing partial or no response to PANSS Scale were included in the study.

Exclusion criteria: Patients were excluded if they have history of diabetes mellitus, hypertension, dyslipidaemia, arrhythmia, epilepsy or alcohol or drug dependence. Pregnant or breast feeding women and women in reproductive age group not using reliable method of contraceptive were also excluded. Patients well maintained on olanzapine monotherapy are also excluded.

Sample size was calculated by using level of significance $\alpha=5 \%$ and power $80 \%$. The difference in cognitive functions of 0.25 was taken from previous studies. The calculated sample size came to be 27 in each group. So the study sample size was rounded to 90 (30 patients in each group) considering future rate of drop outs.

\section{Study procedure}

Patients attending psychiatry OPD were screened and all diagnosed patients of schizophrenia by DSM-IV diagnostic criteria that are on olanzapine therapy for at least 6 weeks showing partial or no response to the treatment which is measured in terms of PANSS scale and those found meeting the inclusion criteria were taken into the consideration. The brief information about the trial was given to all participants and written informed consent was obtained from those willing to participate in the study. This study was approved by institutional ethics committee.

\section{Randomization and blinding}

Double blinding was done by inserting aripiprazole or paliperidone or placebo tablet in a non-transparent capsule. These capsules were given to a third person not directly involved in this study for randomization. All patients received open label tablet olanzapine $10 \mathrm{mg}$ orally daily in the morning with breakfast. In addition, all have received one capsule filled with either aripiprazole 
$10 \mathrm{mg}$, or paliperidone $3 \mathrm{mg}$ or placebo once a day. The randomized treatment allocation sequence was generated by statistician using random number table. It was handed over along with identical plastic containers filled with the study drugs (45 capsules each of aripiprazole or paliperidone or placebo) to a third person not directly involved in this study. This person labeled the containers according to the random allocation sequence of patients with drugs provided. The code of this random allocation sequence was retained in the sealed envelope by this person and was opened only after the completion of study during analysis of data. The patient as well as the investigator was unaware of the treatment being administered. Doses of study drugs were obtained from data of previous studies. ${ }^{1,23-27}$ Figure 1 shows visit and assessment flow chart.

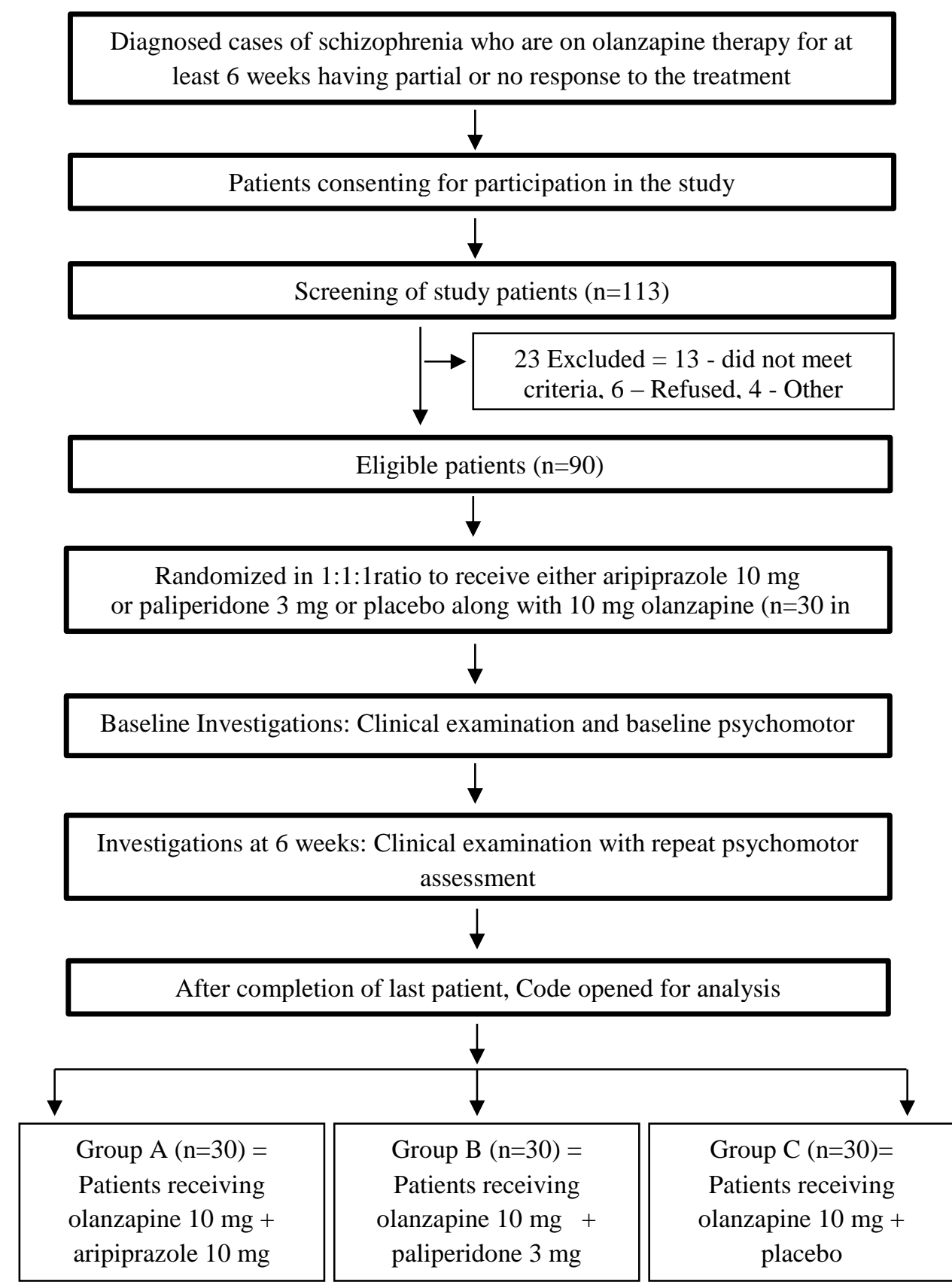

Figure 1: Visit and assessment flow chart.

All the patients were asked to report in psychiatry OPD with empty wrappers of the tablets after 6 weeks for evaluation by the psychiatrist and repeat psychomotor tests. Compliance to the drug was measured by counting remaining tablets in the wrapper at follow up. Patients were also informed to report any time in case of any abnormal events. No other psychiatric drug therapy was given to the patients during the study period. 


\section{Neurocognitive battery}

The neurocognitive test battery is administered at baseline and end of 6 weeks. The neurocognitive tests were chosen to represent a range of reliable and validated tests which have already been used in similar trials.

\section{A test of Attention: Digit symbol substitution test $(D S S T)^{28}$}

Subjects were presented with a sheet of 200 randomized digits (0-9) arranged in 10 rows and 20 columns. In the space below each digit, subjects were required to insert the corresponding symbol. The subjects were asked to substitute as many digits as possible with symbols in the specified time of 2 minutes.. The number of correct substitutions on the sheet was scored.

\section{A test of Perception: Six digit cancellation test $(S D C T)^{28}$}

Subjects were presented with a sheet of 300 randomized digits arranged in 20 columns and 15 rows. Each sheet had six target digits printed on the top. Subjects were given 2 minutes to cancel as many target digits as possible and mark the point up to which the cancellations are attempted. The number of correct cancellations was scored.

\section{Test for central integration: Critical flicker fusion test $(C F F T)^{29}$}

The test of integration was by critical flicker fusion apparatus. The apparatus is basically a viewing tube at the end of which a red circle of light capable of flickering at rate of 5-50 cycles/sec is projected on to a nonreflecting surface. Red light with $100 \%$ brightness was chosen. The flicker frequency range of the instrument is 5-50 Hz. The flicker 'automatic mode' was chosen for the study. This increases the frequency at the rate of 2 $\mathrm{Hz} / \mathrm{sec}$. Critical fusion and flicker frequency is determined and its mean is calculated.

\section{Test of Processing: Arithmetic ability $(A A)^{28}$}

Subjects were asked to solve mathematical problems involving addition, subtraction, multiplication and division (4 of each). All problems involved two digits. Division had to be carried to 2 decimal points. The time allotted for this test was 2 minutes. Two points were given for multiplication and division, while one point for subtraction and addition. The problems were randomly distributed through the sheet in 4 rows and 4 columns. The subjects were asked to go row wise or column wise, as found convenient by the subject. Score was given depending on number of correct problems solved.

5. Test of thinking and processing speed: Verbal fluency test $(V F T)^{30}$
Tests of verbal fluency assess verbal productivity under selected search conditions. For the current study, verbal fluency was assessed under two conditions. In the letter (phonological) fluency condition, subjects were asked to generate as many words as possible that begin with a certain letter of the alphabet (e.g., F A and S). In the category (semantic) fluency condition, subjects were asked to generate as many exemplars of a particular category (e.g., animals, fruits, and vegetables). All trials were $1 \mathrm{~min}$ in length. VFT score is calculated by addition of scores of phonological and semantic conditions.

\section{A test for memory: Digit span test $(D S T)^{31}$}

The subjects were asked to write down a 9 digit sequence after 10 seconds of hearing it. 5 such different sequences were repeated thrice and the score was given on number of correct number placements in each sequence. In any one sequence, digits 1-9 were used randomly without any repetition. The time allotted to recall and write each sequence was 30 seconds. The total time thus required for administration of this test was approximately 25-30 minutes. Maximum score was 135 .

\section{A test for Steadiness: Hand steadiness test $(H S T)^{32}$}

The hand steadiness was tested on the steadiness tester- a device with a series of holes (Whipples holes) of varying size (6 holes with diameters ranging from $4 \mathrm{~mm}$ to 10.5 $\mathrm{mm})$, a stylus and a digital counter. The subject was asked to hold the stylus inserted (the whole length of the metallic portion) in the fourth hole for 15 seconds and was instructed to avoid the contact of the stylus with boundaries of the hole as far as possible. The number of errors was displayed as the contact time in milliseconds at the counter.

\section{Test for motor speed: Finger tapping test $(F T T)^{33,34}$}

Subjects were seated comfortably at a table on which the finger tapper was placed. They were instructed to tap as fast as possible for $10 \mathrm{sec}$, using the index finger of their preferred or dominant hand first. Number of taps in 10 seconds is counted.

\section{Clinical assessment}

It is done with the help of positive and negative symptom scale. The PANSS includes 30 items on three subscales: 7 items covering positive symptoms, 7 covering negative symptoms and 16 covering general psychopathology. Each item is score on a seven point item-specific Likert scale ranging from 1 to 7 ; positive and negative subscale each range from 7 to 49, and the general psychopathology scale from 16 to 112 . The minimum score of total PANSS scale is 30 and maximum is 210 . Record the total score and compare the total score from one evaluation to the next as the measure of response to treatment. 


\section{Statistical Analysis}

Statistical analysis was done in consultation with the statistician. Mean values of change in respective psychomotor tests and PANSS were analyzed within the groups by paired ' $t$ ' test and in between groups by one way ANOVA followed by Turkey's post hoc test. Two tailed $\mathrm{P}$ value were used throughout and $\mathrm{P}<0.05$ was considered as statistically significant in all analyses. We used GRAPH PAD PRISM version 5.0 for statistical analysis.

\section{RESULTS}

In this study, out of 113 patients screened, 90 patients satisfying inclusion criteria were enrolled and randomized. All the randomized patients in each group have satisfactorily completed the study. Baseline characteristics for randomized patients are shown in Table 1.

\section{Cognition and psychomotor assessment}

Table 2 represents changes in cognition and psychomotor function tests in respective groups from baseline to 6 weeks. It shows that, group A (Olanzapine + Aripiprazole) has shown significant improvement in all the tests of cognitive and psychomotor function except hand steadiness test, while group B (olanzapine + paliperidone) has shown improvement in digit symbol substitution test, six digit cancellation test and digit span test only. Group C (olanzapine + placebo) has not shown improvement in any of the parameters at end of 6 weeks.

Table 1: Baseline characteristics for randomized patients.

\begin{tabular}{|llll|}
\hline Characteristic & Group A & Group B & Group C \\
\hline Age & 35.57 & 37.37 & 36.43 \\
& $(11.78)$ & $(12.85)$ & $(11.29)$ \\
\hline Gender & & & \\
Male & 19 & 18 & 20 \\
Female & 11 & 12 & 20 \\
\hline Baseline & 93.77 & 88.03 & 87.60 \\
PANSS score & $(22.37)$ & $(23.93)$ & $(18.58)$ \\
\hline
\end{tabular}

(Values expressed as Mean \pm SD)(PANSS - Positive And Negative Symptoms Scale)

Table 2: Change in cognitive and psychomotor function from baseline to 6 weeks in group A, B, and C.

\begin{tabular}{|lllllll|}
\hline \multirow{2}{*}{ Group } & Group A & & Group B & Group C \\
\hline \multirow{2}{*}{ DSST } & Baseline & 6 Weeks & Baseline & 6 weeks & Baseline & 6 Weeks \\
& 19.23 & $22.20^{* * *}$ & 19.43 & $21.97 * * *$ & 19.37 & 18.57 \\
\multirow{2}{*}{ SDCT } & $(6.907)$ & $(7.170)$ & $(5.691)$ & $(6.457)$ & $(6.729)$ & $(7.319)$ \\
& 41.63 & $44.07 * * *$ & 38.10 & $40.23 * * *$ & 41.07 & 40.37 \\
& $(13.41)$ & $(14.78)$ & $(10.89)$ & $(10.93)$ & $(13.36)$ & $(13.48)$ \\
\hline \multirow{2}{*}{ DST } & 48.13 & $50.23 * *$ & 51.47 & $53.33^{*}$ & 46.53 & 46.03 \\
& $(12.43)$ & $(12.70)$ & $(8.993)$ & $(9.181)$ & $(11.83)$ & $(11.45)$ \\
\hline \multirow{2}{*}{ AA } & 6.333 & $7.300^{* *}$ & 7.667 & 8.100 & 7.633 & 7.100 \\
& $(2.564)$ & $(2.731)$ & $(3.066)$ & $(3.021)$ & $(2.539)$ & $(3.199)$ \\
\hline \multirow{2}{*}{ VFT } & 24.40 & $25.20^{*}$ & 25.57 & 25.33 & 25.50 & 25.13 \\
& $(4.966)$ & $(4.985)$ & $(4.812)$ & $(4.751)$ & $(4.493)$ & $(4.224)$ \\
\hline \multirow{2}{*}{ CFFT } & 35.23 & $35.93 *$ & 34.70 & 35.10 & 35.90 & 35.77 \\
& $(3.213)$ & $(2.900)$ & $(2.806)$ & $(2.695)$ & $(2.721)$ & $(2.788)$ \\
\hline \multirow{2}{*}{ HST } & 486.0 & 445.3 & 572.0 & 542.4 & 489.0 & 476.0 \\
& $(193.1)$ & $(201.3)$ & $(297.9)$ & $(252.6)$ & $(187.4)$ & $(179.7)$ \\
\hline \multirow{2}{*}{ FTT } & 26.20 & $27.23 *$ & 25.63 & 26.27 & 26.40 & 25.90 \\
& $(5.798)$ & $(5.752)$ & $(5.417)$ & $(4.792)$ & $(5.739)$ & $(5.561)$ \\
\hline
\end{tabular}

[Value are expressed as Mean (SD), *** $\mathrm{P}<0.001$, ** $\mathrm{P}<0.01$ and $* \mathrm{P}<0.05$ Vs baseline in respective group]

(DSST -Digit symbol substitution test, SDCT - Six digit cancellation test, DST - Digit span test, AA Arithmetic ability, VFT - Verbal Fluency test, CFFT - Critical flicker fusion test, HST - Hand steadiness test, FTT - Finger tapping test)

Intergroup comparison is shown in Table 3. It shows that group A has shown significant improvement in all the parameters except HST, while group B has shown significant improvement in DSST, SDCT and DST parameters when compared with group C. When Group A is compared with Group B, it has shown significant improvement in AA and VFT only. 
Table 3: Intergroup comparison of mean difference in various tests of cognition and psychomotor function in groups A, B and C from baseline to 6 weeks.

\begin{tabular}{|c|c|c|c|c|c|c|c|c|}
\hline $\begin{array}{l}\text { Test } \\
\text { Group }\end{array}$ & DSST & SDCT & DST & VFT & $\mathbf{A A}$ & CFFT & HST & FTT \\
\hline Group A & $\begin{array}{l}2.967 * * * \\
(2.930)\end{array}$ & $\begin{array}{l}2.433 * * * \\
(2.979)\end{array}$ & $\begin{array}{l}2.100 * \\
(3.346)\end{array}$ & $\begin{array}{l}0.8333^{* \#} \\
(1.895)\end{array}$ & $\begin{array}{l}0.8000^{* * \#} \\
(1.270)\end{array}$ & $\begin{array}{l}0.7000^{*} \\
(1.119)\end{array}$ & $\begin{array}{l}-40.70 \\
(112.5)\end{array}$ & $\begin{array}{l}1.033^{*} \\
(2.282)\end{array}$ \\
\hline Group B & $\begin{array}{l}2.533 * * * \\
(2.675)\end{array}$ & $\begin{array}{l}2.133 * * * \\
(2.417)\end{array}$ & $\begin{array}{l}1.867^{*} \\
(4.273)\end{array}$ & $\begin{array}{l}-0.3667 \\
(0.1938)\end{array}$ & $\begin{array}{l}-0.3667 \\
(1.752)\end{array}$ & $\begin{array}{l}0.4000 \\
(1.303)\end{array}$ & $\begin{array}{l}-29.60 \\
(92.13)\end{array}$ & $\begin{array}{l}0.6333 \\
(2.512)\end{array}$ \\
\hline Group C & $\begin{array}{l}-0.8000 \\
(2.511)\end{array}$ & $\begin{array}{l}-0.7000 \\
(2.806)\end{array}$ & $\begin{array}{l}-0.5000 \\
(3.540)\end{array}$ & $\begin{array}{l}-0.4667 \\
(1.776)\end{array}$ & $\begin{array}{l}-0.9000 \\
(2.155)\end{array}$ & $\begin{array}{l}-0.1333 \\
(1.167)\end{array}$ & $\begin{array}{l}-13.03 \\
(90.98)\end{array}$ & $\begin{array}{l}-0.5000 \\
(2.330)\end{array}$ \\
\hline $\begin{array}{l}\text { One way } \\
\text { ANOVA } \\
\text { F Ratio }\end{array}$ & 17.34 & 11.91 & 4.435 & 6.293 & 3.443 & 3.721 & 0.5932 & 3.360 \\
\hline $\begin{array}{l}\text { One way } \\
\text { ANOVA } \\
\text { P Value }\end{array}$ & $<0.0001$ & $<0.0001$ & 0.0146 & 0.0028 & 0.0364 & 0.0282 & 0.5548 & 0.0393 \\
\hline
\end{tabular}

[Value are expressed as Mean (SD), *** $\mathrm{P}<0.001, * * \mathrm{P}<0.01$ and $* \mathrm{P}<0.05$ Vs group $\mathrm{C}, \# \mathrm{P}<0.05$ Vs group $\mathrm{B}$ ] (DSST -Digit symbol substitution test, SDCT - Six digit cancellation test, DST - Digit span test, AA - Arithmatic ability, VFT - Verbal Fluency test, CFFT - Critical flicker fusion test, HST - Hand steadiness test, FTT - Finger tapping test)

\section{Clinical assessment}

As far as clinical parameter in the form of PANSS score in concerned, both group A and group B has shown significant improvement when compared with the baseline values, as well as with group $C$ at end of 6 weeks. There is no difference between groups $\mathrm{A}$ and $\mathrm{B}$ (Table 4 and Table 5).

Table 4: Change in clinical parameter (PANSS score) from baseline to 6 weeks in group A, B and C.

\begin{tabular}{|lllllll|}
\multicolumn{1}{r}{ Group } & Group A & \multicolumn{3}{c}{ Group B } & \multicolumn{3}{c}{ Group C } \\
\cline { 2 - 7 } Test & Baseline & 6 Weeks & Baseline & 6 weeks & Baseline & 6 Weeks \\
\hline PANSS & 93.77 & $88.27 * * *$ & 88.03 & $83.46^{* * *}$ & 87.60 & 87.83 \\
Score & $(22.37)$ & $(19.64)$ & $(23.93)$ & $(21.66)$ & $(18.58)$ & $(18.71)$ \\
\hline
\end{tabular}

[Value are expressed as Mean (SD), $* * * \mathrm{P}<0.001$ Vs baseline in respective group] (PANSS Positive And Negative Symptoms Scale)

Table 5: Intergroup comparison of mean difference in clinical parameter (PANSS score) in groups A, B and C from baseline to 6 weeks.

\begin{tabular}{|ll|}
\hline \multicolumn{1}{|c|}{ Test } & PANSS Score \\
Group & $-5.500 * * *(6.463)$ \\
\hline Group A & $-4.600 * *(6.595)$ \\
\hline Group B & $0.2333(2.967)$ \\
\hline Group C & 9.096 \\
\hline One way ANOVA F ratio & 0.0003 \\
\hline One way ANOVA P value & 0.003 \\
\hline
\end{tabular}

[Value are expressed as Mean (SD), *** $\mathrm{P}<0.001, * * \mathrm{P}<$ 0.01 Vs group C] )(PANSS - Positive And Negative Symptoms Scale)

\section{DISCUSSION}

Cognition is thought to be under control of dorsolateral prefrontal cortex (DLPFC). Till recently, scientist have found out role of different neurotransmitters like dopamine, glutamate, GABA, glycine, cholinergic system and endocannabinoid as a promising targets to improve cognition in patients of schizophrenia. But apart from dopamine, evidences favouring role of other neurotransmitters are lacking. So the drugs affecting dopaminergic system still remains attractive targets for improvement in cognition. It is now well known that chronic deficiency of dopamine at DLPFC is responsible for cognitive deficits in patients of schizophrenia. Thus, agents raising dopaminergic activity at DLPFC are promising targets to achieve cognitive benefits in patients of schizophrenia. ${ }^{3}$

Neurotransmitter, serotonin has important influences on dopamine, but this influence is quite different in each of the four dopamine pathways. Serotonin inhibits dopamine release from dopaminergic axon terminals in the various dopamine pathways, but the degree of control differs from one dopamine pathway to another. In other words, antagonism at serotonergic receptors especially $5 \mathrm{HT}_{2}$, results in increase release of dopamine in dorsolateral prefrontal cortex. ${ }^{3}$ 
In our study, the reason why aripiprazole had shown significant improvement in most of the cognitive and psychomotor parameters remains in its complex mechanism of action. Aripiprazole, a $\mathrm{D}_{2}$ receptor partial agonist, may also owe some of its atypical properties to its net effect of weak $\mathrm{D}_{2}$ antagonism, 5- $\mathrm{HT}_{2 \mathrm{~A}}$ antagonism and $5-\mathrm{HT}_{1 \mathrm{~A}}$ agonism. ${ }^{35,36}$ Preclinical studies proves beyond doubt that $5-\mathrm{HT}_{2 \mathrm{~A}}$ and $\mathrm{D}_{2}$ receptor blockade promote the ability of $5-\mathrm{HT}_{1 \mathrm{~A}}$ receptor stimulation to increase DLPFC dopamine release, regardless of intrinsic $5-\mathrm{HT}_{1 \mathrm{~A}}$ affinity. ${ }^{37}$ Thus, aripiprazole having $5 \mathrm{HT}_{2 \mathrm{~A}}$ and $\mathrm{D}_{2}$ antagonist as well as $5 \mathrm{HT}_{1}$ agonist activity, would result in more significant increase in dopaminergic activity at DLPFC. ${ }^{35}$ Hence group A has shown improvement in most of the cognitive and psychomotor parameters as compared to other two groups.

Paliperidone on the other hand, is only $5 \mathrm{HT}_{2 \mathrm{~A}}$ and $\mathrm{D}_{2}$ antagonist. It does not have $5 \mathrm{HT}_{1 \mathrm{~A}}$ agonistic activity. Hence, increase in dopaminergic activity by paliperidone at DLPFC would be comparatively lesser than aripiprazole. Thus, group B has shown improvement in only some of the cognitive parameters in our study.

However, while interpreting the present results, the influence of practice effects can not be disregarded. In one of the first trials examining cognitive improvement with second-generation antipsychotics in first-episode schizophrenia patients including healthy controls undergoing repeated testing, the possibility that improvements in cognition might simply reflect practice effects was assessed by Goldberg et.al (2007). ${ }^{38}$ The authors found some of the improvements in cognition in the patient group to be related to practice effects. Taking these aspects into account, we cannot conclude that the cognitive enhancement detected can be totally attributed to the treatment applied. To eliminate practice effects as much as possible, the neurocognitive tests in the study at hand were performed using different parallel versions at every assessment point. Caution is furthermore wanted as no healthy control group was included in the study design limiting further conclusions of the individual influence of the antipsychotic treatment applied. ${ }^{15}$

There is optimism in the field that improvements in cognition such as verbal learning will lead to improvements in real world functioning. However, it is unknown whether changes in cognition will lead directly to improvements in functional outcome in patients with schizophrenia. It may be more likely that changes in cognition will enable patients to acquire component skills (e.g. coping strategies and communication skills) necessary to succeed in the workplace or social environments and the incorporation of these skills in their daily lives will lead to improvements in work and social functioning. ${ }^{14,39}$

\section{Positive and negative symptom scale (PANSS)}

In the present study, both combinations were found to be effective in controlling symptoms of schizophrenia as compared to olanzapine and placebo treatment. There was a significant decrease in PANSS score in both group A and group B from baseline to 6 weeks, while group C shows nonsignificant increase in performance (Table 18). Intergroup comparison revealed significant decrease in mean PANSS score after 6 weeks, when both group A and group B are compared with group C. But there was no significant difference in mean PANSS score when group $\mathrm{A}$ and group B are compared. There was much reduction in negative symptoms as compared to positive symptoms in our study, finding similar to previous studies.

In their research work, Potkin SG et al (2003), ${ }^{13}$ Swainston Harrison T, Perry CM (2004) ${ }^{23}$ and Findling $\mathrm{RL}$ et al $(2008)^{25}$ also found that aripiprazole significantly reduces positive as well as negative symptoms of schizophrenia, especially the later. Hughes D (2008), ${ }^{40}$ given a case report showing beneficial effect of aripiprazole $10 \mathrm{mg}$ added to olanzapine $10 \mathrm{mg}$ significantly improved negative symptoms of the patient, scenario similar to our study. Similarly, results shown by paliperidone in our study are also comparable with previous studies. Marder SR et al (2007), ${ }^{41}$ Kane J et al. $(2007),{ }^{42}$ Turkoz I et al $(2009)^{43}$ and Chwieduk CM (2010), ${ }^{19}$ in their 6 weeks studies found that paliperidone is effective in reducing positive and negative symptoms of schizophrenia as assessed by PANSS.

Aripiprazole is $5 \mathrm{HT}_{2 \mathrm{~A}}$ antagonist and having variable $\mathrm{D}_{2}$ action according to level of dopamine ${ }^{44,45}$ while paliperidone is $5 \mathrm{HT}_{2 \mathrm{~A}}$ as well as $\mathrm{D}_{2}$ antagonist. ${ }^{27}$ Both agents will raise dopamine levels at prefrontal cortex. This explains the reason behind their overall improvement in PANSS as compared to placebo.

Decreased PANSS negative score significantly influenced by favorable functioning in cognitive domains of working memory, reaction time, psychomotor speed etc. Thus, improvement in those cognitive domains has significant positive impact in reducing PANSS score, especially the negative symptoms. These findings are consistent with studies of Heydebrand et al (2004). ${ }^{46}$

Though we have maximally tried to reduce the practice effects, its influence can not be totally ignored. The finding on cognition reflects enhanced practice effects and not the benefit from learning per se. However, it should be noted that patients of schizophrenia show minimal practice effects on learning. Secondly, though the results of our study showed significant improvement in cognition and psychomotor functions in 6 weeks with both the combinations, long duration studies are needed to examine whether these effects are long lasting or not.

\section{CONCLUSION}

Results of present study showed that the combination of aripiprazole and olanzapine has shown significant 
improvement in most of the cognitive and psychomotor parameters such as attention, perception, verbal memory, thinking and processing and motor speed, while only attention, perception and verbal memory parameters were improved by combination therapy with paliperidone and olanzapine for period of 6 weeks. As far as clinical parameter in form of PANSS score is concerned, both the combinations were effective in reducing positive and negative symptoms of schizophrenia at the end of study and results were significant as compared to olanzapine and placebo treatment.

Hence, the best augmenting strategy with for olanzapine nonresponsive patients will be $\mathrm{D}_{2}$ receptor partial agonist like aripiprazole rather than $\mathrm{D}_{2}$ antagonist like paliperidone and other atypical antipsychotic agents for better improvement in cognition and psychomotor domains.

Funding: No funding sources

Conflict of interest: None declared

Ethical approval: The study was approved by the institutional ethics committee

\section{REFERENCES}

1. Reus VI. Mental disorders. Harrison's principles of internal medicine, 17th ed. Kasper DL, Braunwald E, Fauci AS, Hauser SL, Longo DL, Jameson JL, et al., editors. New York: Mc Graw Hill; 2008: 2710-2723.

2. Stahl SM. Essential psychopharmacology neuroscientific basis and practical application. 2nd ed. Cambridge: University Press; 2004: 365-458.

3. Lesh TA, Niendam TA, Minzenberg MJ and Carter CS. Cognitive control deficits in schizophrenia: Mechanisms and meaning. Neuropsychopharmacology. 201136(1):316-38.

4. Weickert TW, Goldberg TE. First and second generation antipsychotic medication and cognitive processing in schizophrenia. Curr Psychiatry Rep. 2005;7(4):304-10.

5. Morrens M, Hulstijn W, Sabbe B. Psychomotor slowing in schizophrenia. Schizophr Bull. 2007;33:1038-53.

6. Baldessarini RJ, Tarazi I. Pharmacotherapy of psychosis and mania. In: Goodman and Gilman's the pharmacological basis of therapeutics. Brunton LL, Lazo JS, Pasrker KL, editors. New York: McGraw Hill; 2005: 461-500.

7. Zink M. Augmentation of olanzapine in treatmentresistant schizophrenia. J Psychiatry Neurosci. 2005;30(6):409-15.

8. Lerner V, Libov I, Kotler M, Strous RD. Combination of "atypical" antipsychotic medication in the management of treatment-resistant schizophrenia and schizoaffective disorder. Prog Neuropsychopharmacol Biol Psychiatry. 2004;28(1):89-98.

9. Kane JM, Correll CU, Goff DC, Marder SR, Wei Sun, Kirkpatrick B, et al. A multicentre randomised double blind placebo controlled 16 week study of adjunctive aripiprazole for schizophrenia and schizoaffective disorder inadequately treated with quetiapine or risperidone monotherapy. J Clin Psychiatry. 2009;70(10):1348-57.

10. Herbert Meltzer. (2009) Antipsychotic agents and lithium. In: Basic and clinical pharmacology. 11th edi. Katzung BG, Masters SB, Trevor AJ editors; 2009: 487-508.

11. Burris KD, Molski TF, Xu C, Ryan E, Tottori K, Kikuchi T. et al. Aripiprazole, a novel antipsychotic, is a high affinity partial agonist at human dopamine D2 receptors. J Pharmacol Exp Ther. 2002;302:3819.

12. Jordan S, Koprivica V, Chen R, Tottori K, Kikuchi $\mathrm{T}$, Altar CA. The antipsychotic aripiprazole is a potent, partial agonist at the human 5-HT1A receptor. Eur J Pharmacol. 2002;441:137-40.

13. Potkin SG, Saha AR, Kujawa MJ, Carson WH, Mirza A, Stock E. et al. Aripiprazole, an antipsychotic with a novel mechanism of action, and risperidone vs placebo in patients with schizophrenia and schizoaffective disorder. Arch Gen Psychiatry. 2003;60:681-90.

14. Robert S. Kern, Michael F. Green, Barbara A. Cornblatt, J. Randall Owen, Robert D. McQuade, William H. Carson et al. The neurocognitive effects of aripiprazole: an open-label comparison with olanzapine. Psychopharmacology. 2006;187:312-20.

15. M. Riedel, R. Schennach-Wolff, R. Musil, S. Dehning, A. Cerovecki, M. Opgen-Rhein, J. et al. Neurocognition and its influencing factors in the treatment of schizophrenia - effects of aripiprazole, olanzapine, quetiapine and risperidone. Hum. Psychopharmacol Clin Exp. 2010;25:116-25.

16. The neurocognitive effects of aripiprazole compared with risperidone in the treatment of schizophrenia. Hiroshima J Med Sci (Japan). 2012;61(4):75-83.

17. Marder SR, McQuade RD, Stock E, Kaplita S, Marcus R, Safferman AZ. et al. Aripiprazole in the treatment of schizophrenia: safety and tolerability in short-term, placebo-controlled trials. Schizophr Res. 2003;61:123-6.

18. Belgamwar RB, El-Sayeh HG: Aripiprazole versus placebo for schizophrenia. Cochrane Database Syst Rev (England). 2011.

19. Chwieduk CM, Keating GM. Paliperidone extended release: a review of its use in the management of schizophrenia. Drugs. 2010;70(10):1295-317.

20. Houthoofd SA, Morrens M, Sabbe BG. Cognitive and psychomotor effects of risperidone in schizophrenia and schizoaffective disorder. Clin Ther. 2008;30(9):1565-89.

21. Harvey PD, Napolitano JA, Mao L, Gharabawi G. Comparative effects of risperidone and olanzapine on cognition in elderly patients with schizophrenia or schizoaffective disorder. Int $\mathbf{J}$ Geriatr Psychiatry. 2003;18(9):820-9.

22. Keefe RS, Bilder RM, Davis SM, et al. Neurocognitive effects of antipsychotic medications 
in patients with chronic schizophrenia in the CATIE Trial. Arch Gen Psychiatry (United States). 2007;64(6):633-47.

23. Swainston Harrison T, Perry CM. Aripiprazole: a review of its use in schizophrenia and schizoaffective disorder. Drugs. 2004;64(15):1715-36.

24. Mucci Armida, Piegari Giuseppe and Galderisi Silvana. Cognitive enhancing effects of aripiprazole : a case report. Clin Pract Epidemiol Ment Health. 2008;4:24.

25. Findling RL, Robb A, Nyilas M, Forbes RA, Jin N, Ivanova $\mathrm{S}$ et al. A multiple-center, randomized, double-blind, placebo-controlled study of oral aripiprazole for treatment of adolescents with schizophrenia. Am J Psychiatry. 2008;165(11):143241.

26. Fowler JA, Bettinger TL, Argo TR. Paliperidone extended-release tablets for the acute and maintenance treatment of schizophrenia. Clin Ther. 2008;30(2):231-48.

27. Yang LP. Oral paliperidone: a review of its use in the management of schizoaffective disorder. CNS Drugs. 2011;25(6):523-38.

28. Stone BM. Pencil and paper tests- sensitivity to psychotropic drugs. $\mathrm{Br} \mathrm{J}$ Clin Pharmacol. 1984;18:15S-20S.

29. Turner P. Critical flicker fusion frequency and centrally acting drugs. Br J Ophth. 1968;52:245-50.

30. Spreen O, Benton AL. Neurosensory center comprehensive examination for aphasia (NCCEA) (revised edition). University of Victoria, Neuropsychology Laboratory, Victoria, British Columbia. 1997.

31. McClelland GR, Cooper SM, Pilgrim AJ. A comparison of the central nervous system effects of haloperidol, chlorpromazine and sulpiride in normal volunteers. Br J Clin Pharmacol. 1990;30:795-803.

32. Kaur G, Sandhu SS, Sandhu SS. Comparison of armhand steadiness for shooting perfection in armed forces and Punjab police. Anthropologist 2007;9(4):299-304.

33. Sjøgren P, Christrup LL, Petersen MA, Højsted J. Neuropsychological assessment of chronic nonmalignant pain patients treated in a multidisciplinary pain centre. Eur J Pain. 2005;9(4):453-62.

34. George P. Prigatano, Beate Hoffmann. Finger Tapping and Brain Dysfunction: A Qualitative and Quantitative Study. Borrow Quarterly. 1997;13(4).

35. Li Z, Ichikawa J, Dai J, Meltzer HY. Aripiprazole, a novel antipsychotic drug, preferentially increases dopamine release in the prefrontal cortex and hippocampus in rat brain. Eur $\mathrm{J}$ Pharmacol. 2004;493(1-3):75-83.
36. Meltzer HY, Li Z, Kaneda Y, Ichikawa J. Serotonin receptors: their key role in drugs to treat schizophrenia. Prog Neuropsychopharmacol Biol Psychiatry. 2003;27(7):1159-72.

37. Ichikawa J, Ishii $\mathrm{H}$, Bonaccorso $\mathrm{S}$, Fowler WL, O'Laughlin IA, Meltzer HY. 5-HT(2A) and D(2) receptor blockade increases cortical DA release via 5-HT(1A) receptor activation: a possible mechanism of atypical antipsychotic-induced cortical dopamine release. J Neurochem. 2001;76(5):1521-31.

38. Goldberg TE, Goldman RS, Burdick KE, Malhotra AK, Lencz T, Patel RC et al. Cognitive improvement after treatment with second-generation antipsychotic medications in first-episode schizophrenia: is it a practice effect? Arch Gen Psychiatry. 2007;64(10):1115-22.

39. Green MF, Kern RS, Braff DL, Mintz J. Neurocognitive deficits and functional outcome in schizophrenia: are we measuring the right stuff? Schizophr Bull. 2000;26:119-36.

40. D. Hughes and M. Morcos. Use of aripiprazole in treatment resistant schizophrenia. J Psychopharmacology. 2008;22:927.

41. Marder SR, Kramer M, Ford L, Eerdekens E, Lim $\mathrm{P}$, Eerdekens $\mathrm{M}$, et al. Efficacy and safety of paliperidone extended-release tablets: results of a 6week, randomized, placebo-controlled study. Biol Psychiatry. 2007;62(12):1363-70.

42. Kane J, Canas F, Kramer M, Ford L, GassmannMayer C, Lim P et al. Treatment of schizophrenia with paliperidone extended-release tablets: a 6-week placebo-controlled trial. Schizophr Res. 2007;90(13):147-61.

43. Turkoz I, Bossie CA, Dirks B, Canuso CM. Direct and indirect effects of paliperidone extended release tablets on negative symptoms of schizophrenia. Neuropsychiatric Disease and Treatment. 2008;4(5):949-58.

44. Chavda RK, Laxmi L, Nair BS, Gandewar K. Efficacy and Tolerability of Aripiprazole in Patients with Schizophrenia \& Schizoaffective Disorders. Indian Journal of Psychiatry. 2004;46(2):150-5.

45. Croxtall JD: Aripiprazole: a review of its use in the management of schizophrenia in adults. CNS Drugs (New Zealand). 2012;26(2):155-83.

46. Heydebrand G, Weiser M, Rabinowitz J, Hoff AL, De Lisi LE, Csernansky JG. Correlates of cognitive deficits in first episode schizophrenia. Schizophr Res. 2004;68:1-9.

doi:10.5455/2319-2003.ijbcp20140216

Cite this article as: Mayabhate MM, Badar VA, Waradkar P, Somani A. Cognitive and psychomotor effects of adjunctive aripiprazole or paliperidone in patients of schizophrenia receiving olanzapine: a double blind placebo controlled clinical study. Int $\mathbf{J}$ Basic Clin Pharmacol 2014;3:130-8. 